\title{
Uniaxial Tensile Tests to Measure the Bond of In Situ Concrete Overlays
}

Robert G. Mathey
Lawrence I. Knab
${ }^{1}$ Guest Researcher, NIST
${ }^{2}$ Research Civil Engineor, NIST

U.S. DEPARTMENT OF COMMERCE Natlonal Instltute of Standards and Technology Bullding and Fire Research Laboratory Bullding Materlals Division Galthersburg, MD 20899

Sponsored by: Tri-Servlce Bullding Materlals Investigational Program Headquarters, U.S. Army Corps of Engineers Washington, DC 20314-1000 U.S. Navy, Naval Facllitles Englineering Command Alexandrla, VA 22332-1000 Headquarters, U.S. Alr Force, Englneoring and Servlces Bolling Alr Force Base, DC 20332-5000
U.S. DEPARTMENT OF COMMERCE Robert A. Mosbacher, Secretary NATIONAL INSTIUUTE OF STANDARDS AND TECHNOLOGY

John W. Lyons, Director

$-Q C$

100

.456

\#4648 



\section{Uniaxial Tensile Tests to Measure the Bond of In Situ Concrete Overlays}

Robert G. Mathey ${ }_{2}^{1}$

${ }^{1}$ Guest Researcher, NIST

${ }^{2}$ Research CIvll EngIneer, NIST

U.S. DEPARTMENT OF COMMERCE Natlonal Instrtute of Standards and Technology

Bullding and Fre Research Laboratory Bullding Materlals DivlsIon Calthersburg, MD 20899

Sponsored by:

Trh-Servlce Bullding Materlals Investigational Program Headquarters, U.S. Army Corps of Engineers Washington, DC 203141000 U.S. Navy, Naval Facillties Engineoring Command Alexandrla, VA 22332-1000 Headquarters, U.S. Alr Force, Engineering and Services Bolling Alr Force Base, DC $20332-5000$

October 1991

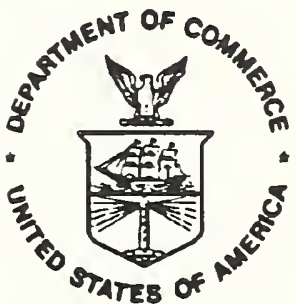

U.S. DEPARTMENT OF COMMERCE Robert A. Mosbacher, Secretary NATIONAL INSTITUTE OF STANDARDS AND TECHNOLOGY

John W. Lyons, Director 



\section{Abstract}

The feasibility of two in situ tensile test methods for use in the field to measure the bond of concrete overlays was investigated in the laboratory. The two test methods used pneumatic and hydraulic loading apparatuses. The uniaxial tensile tests were conducted using partial-depth in situ cores drilled through overlay concrete and into previously cast slabs. Comparisons of the magnitude and repeatability of the tensile strength results for the two test methods indicated that they were comparable. The study demonstrated that both the pneumatic and hydraulic test methods are applicable for field use for measuring the tensile strength of the bond between a relatively thick overlay and its base concrete.

Key Words: bond, concrete, in situ, overlays, repair materials, tensile strength, test methods 


\section{Table of Contents}

1. Introduction $\ldots \ldots \ldots \ldots \ldots \ldots \ldots \ldots \ldots \ldots \ldots \ldots \ldots \ldots \ldots \ldots \ldots \ldots$

2. Bond Strength Test Methods for Repair Materials .... 1

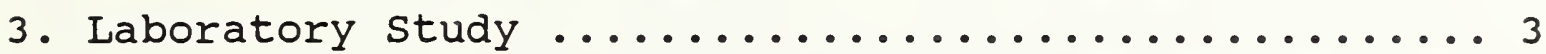

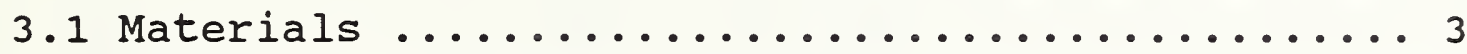

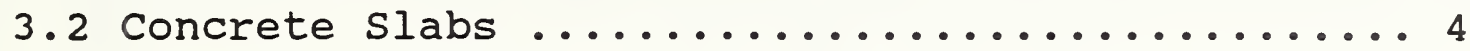

3.3 Test Apparatus and Procedures .............. 5

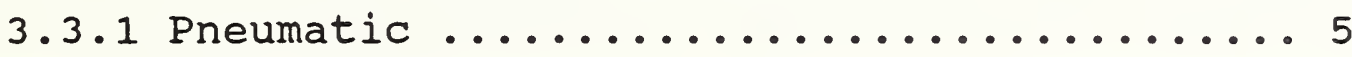

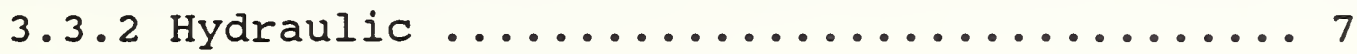

4. Test Results .............................

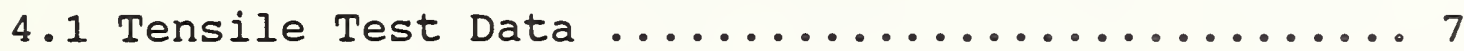

4.2 Data Analysis and Discussion ............... 8

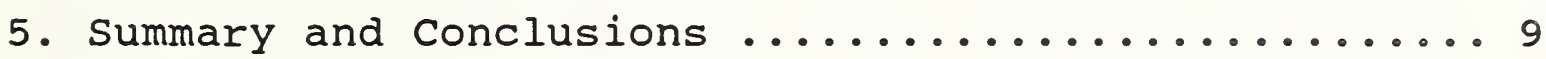

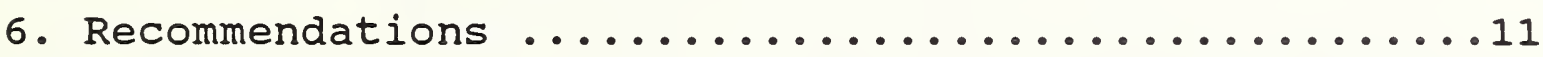

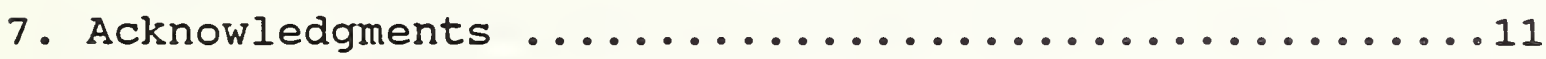

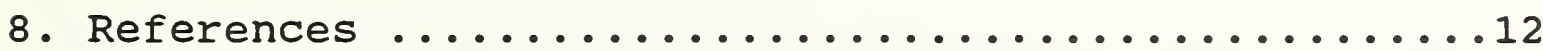




\section{List of Tables and Figures}

Table 1. Mix Proportions and Properties of Fresh Base and overlay Concrete .................... 14

Table 2. Compressive Strength and Age of Base and

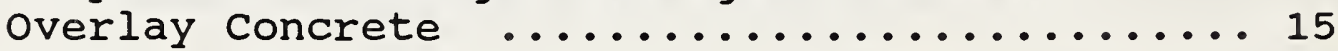

Table 3. Tensile Test Data for slab Number $1 \ldots . . \ldots 16$

Table 4. Tensile Test Data for Slab Number 2 ....... 17

Table 5. Tensile Test Data for Slab Number $3 \ldots \ldots$

Table 6. Summary of Tensile Test Data ............ 19

Figure 1. Typical Concrete Slab Used for the Tensile

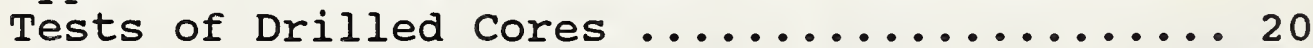

Figure 2. Sketch of Cross-section of Pneumatic

Apparatus Attached to an Isolated Core ..... 21

Figure 3a. Pneuamtic Apparatus Positioned for Testing .. 22

Figure 3b. Pneumatic Apparatus with Attached Rubber

Sheet to Reduce Movement at Failure and

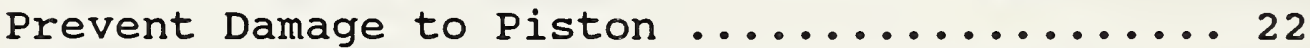

Figure 4. Heise Air Pressure Gauge with Pacing Dial

used to Pressurize Piston Air Chamber at

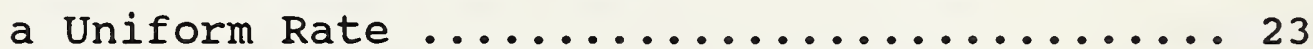

Figure 5. Sketch of Cross-Section of Calibration

Setup for Pneumatic Appratus ............ 24

Figure 6. Hydraulic Apparatus Positioned for Testing .. 25

Figure 7. Tensile Core strength Data for Overlay Over

Base Concrete (O/B), Overlay Concrete

Only (O), and Base Concrete only (B) ...... 26

Figure 8. Failed Cores from slab No. 1 ............ 27

Figure 9. Failed Cores from slab No. $2 \ldots \ldots \ldots \ldots . \ldots . \ldots 28$

Figure 10. Failed Cores from slab No. $3 \ldots \ldots . . . . . . .29$ 


\section{Introduction}

The strength of the bond between repair materials and existing concrete is a major factor in the performance of repaired concrete structures. There is a need for a repeatable field test method to measure the tensile strength of this bond. Two in situ test methods to measure the uniaxial tensile bond strength of concrete overlays were investigated in the laboratory to determine their feasibility for field use. Comparisons were made of the magnitude and repeatability of the bond strength results for the two test methods. It is noted that the feasibility of using another hydraulic apparatus, similar to the one investigated in this report, has been demonstrated to measure tensile bond strength of concrete overlays (see section 2).

In this report,"in situ" refers to drilling a core through an overlay and a small distance into its base concrete and then testing the tensile strength of the intact core, rather than removing the core and testing it elsewhere. These in situ test methods have the advantage of providing results in the field compared with the presently used method of drilling cores and testing them in shear in the laboratory.

The two methods investigated were based on either a hydraulic or pneumatic apparatus. The hydraulic uniaxial tensile test apparatus was a modification of the ACI 503R field test apparatus [1] for measuring the adhesion between cured epoxy or other polymeric compounds and concrete. A small, portable, pneumatic apparatus was developed at the National Institute of Standards and Technology (NIST) for measuring the adhesion of protective coatings to substrates $[2,3]$. This apparatus was modified for in situ measurements of the tensile bond strength of concrete cores which were drilled through concrete overlays and into base concrete.

Compared with the hydraulic test apparatus, the pneumatic test apparatus offers the potential of minimizing or eliminating the effects of eccentric load and of more accurately controlling the rate of load application. Both of the test methods investigated in this laboratory study can potentially be used to develop or validate performance criteria, to accept or reject an overlay installation, to gain information on the possible deterioration of the overlay-substrate bond with time, to evaluate different overlays in the laboratory, and to correlate laboratory test data with field performance of overlays.

\section{Bond Strength Test Methods for Repair Materials}

A brief review of some of the test methods for determining the bond of repair or overlay concrete materials to existing concrete is presented. Some of these test methods are used extensively while others have had little use in the field. 
In recent years there have been a number of reports dealing with test methods to assess or evaluate the bond between repair materials and existing concrete. Included in this category of test methods are procedures for measuring the bond between concrete overlay materials and existing or base concrete in pavements. Bond strength of repair and overlay concrete materials have been measured both in laboratory and field tests. These tests have included taking field core samples and measuring the bond by means of shear tests in the laboratory, or by an in situ tensile bond test performed in the field. Currently the bond between concrete overlay materials and existing concrete pavement is generally determined in the laboratory using shear tests of concrete cores $[4,5,6]$.

In a recent evaluation of repair materials with regard to selection criteria, a number of currently used adhesion/bond test methods were considered, including direct tension, direct pull-off, flexure, direct shear, and slant shear [7]. The slant-shear test was viewed as the most reliable method. It is noted that the slant-shear test is a laboratory test and is not applicable as an in situ field bond test. In another study [8], four test methods were evaluated: slant shear, indirect tension, and two flexural test methods. It was found that the slant shear test method was the most appropriate and was therefore used to assess the effects of various parameters on the bond strength between new and old concrete. In a study to evaluate spall repairs [9], specimens were damaged by pullout testing of a metal insert embedded in concrete. The concrete was repaired with epoxy mortar and subjected to pullout testing again. The study showed that the overriding factor governing successful repairs to concrete was the soundness of the repair plane. Knab and spring [10] investigated the bond strength of concrete repair materials using a slant-shear test method and two methods for measuring the uniaxial tensile bond strength of laboratory-prepared specimens.

Various test methods were reviewed by Knab [11] with regard to their use in standards, specifications, and investigations of concrete repair materials. All of the tests reviewed are conducted in the laboratory, except the in situ tensile bond or adhesion test method $[1,12]$. Preliminary performance criteria were developed for screening and selecting portland cement concrete (PCC) and latexmodified concrete (LMC) materials to be overlaid on PCC pavements and bridge decks [6]. The criteria were developed using the direct shear bond test method and were based on direct shear bond strengths of PCC and LMC overlays using cores from pavements and bridge decks and laboratory- and field-cast specimens. Two common direct shear bond test methods are described in Reference Nos. 4 and 13 .

A light, portable, hydraulic apparatus, similar to the ACI 503R apparatus, was applied by Causey [14] to measure the bond of concrete overlay repair materials. The tests were intended to 
evaluate the quality of concrete repair materials. The overlays included portland cement and polymer modified concretes, which were considerably thicker than the relatively thin epoxy concrete overlays described in ACI 503R [1]. Hindo [15] used the same type of apparatus as causey in carrying out in situ direct tensile tests to evaluate the bond strength between overlay concrete and the existing base concrete. A somewhat similar in situ hydraulic test method has been used to evaluate the bond of repair materials to surfaces at any angle, including horizontal and vertical surfaces [16]. Examples of the use of mechanical in situ tensile bond or pull off test methods are given in Reference Nos. 17-19.

Another pneumatic apparatus, in addition to the one developed at NIST [2,3], was a device used to measure the tensile bond between plaster and concrete and between grout and masonry block [20].

\section{Laboratory study}

Three concrete slabs with overlays of different compressive strengths were cast and cured. Cores were drilled through the overlay concrete and a small distance into the base concrete. A steel disk was adhered to the top of the intact core using a high strength, quick-set epoxy. The disk was attached to the hydraulic or pneumatic apparatus and the core was pulled uniaxially by steadily increasing the hydraulic or air pressure. The failure occurred either at the bond line, in the overlay concrete or in the base concrete. A failure occurring at a location other than at the bond plane indicated that the bond strength of the overlay to its base concrete exceeded the tensile strength at the location of failure. Also, cores were drilled into overlay concrete only and base concrete only, and the uniaxial tensile strengths of the overlay and the base concretes were determined.

The materials and procedures used to cast the slabs, a description of the slabs, and the test apparatus and procedures used to conduct the tensile tests are presented in this section of the report.

\subsection{Materials}

The base concrete in the three slabs was portland cement concrete (PCC). The overlay concrete in two of the slabs was PCC and latex modified concrete (LMC) was used in the other slab. A sketch of a typical concrete $s$ lab is shown in Figure 1 . At the time of testing, the age of the base concrete in the three slabs ranged from 48 to 76 days and the age of the overlay concrete ranged from 7 to 28 days. The ranges in strength of the base and overlay concretes in the three slabs were 30.3 to $31.8 \mathrm{MPa}(4390$ to 4620 psi) and 24.4 to $32.9 \mathrm{MPa}$ (3540 to $4770 \mathrm{psi}$ ), respectively. $\mathrm{Mix}$ proportions and properties of the fresh base and overlay concretes are given in Table 1. The compressive strengths of the base and 
overlay concrete are given in Table 2. The base and overlay concretes were made using ASTM Type I portland cement, siliceous concrete sand, and $19 \mathrm{~mm}$ (3/4 in.) maximum size crushed stone coarse aggregate. The concrete was mixed in a $0.25-\mathrm{m}^{3}\left(9-\mathrm{ft}^{3}\right)$ capacity drum type mixer. Batch volumes for the base and overlay concretes were 0.18 and $0.15 \mathrm{~m}^{3}\left(6.5\right.$ and $\left.5.3 \mathrm{ft}^{3}\right)$, respectively. Mixing time was about 7 minutes. The density of the fresh base concrete in slab No. 1 was $2280 \mathrm{~kg} / \mathrm{m}^{3}\left(142 \mathrm{lbm} / \mathrm{ft}^{3}\right)$. A water reducing admixture was used only in the first base concrete cast (Slab No. 3), and it was found that it was not needed in subsequent base and overlay concrete batches.

\subsection{Concrete Slabs}

One half of each of the three slabs had overlay concrete cast over base concrete, one quarter of the slab had base concrete only, while the other quarter of the slab had overlay concrete only (Figure 1).

Base concrete was cast in wood forms that were $1400 \times 1400 \mathrm{~mm}$ (56 $x 56$ in.) in length and width and $100 \mathrm{~mm}$ ( 4 in.) deep. One quadrant of the wood form, $710 \times 710 \mathrm{~mm}(28 \times 28$ in.), did not contain base concrete but was reserved to be used later for overlay concrete. Reinforcing bars, No. 4 size, were spaced $200 \mathrm{~mm}$ ( 8 in.) apart in both directions of the forms as shown in Figure 1. The bars were placed at mid depth of the forms and they extended the entire length and width of the forms (1400 mm (56 in.)).

A 50-mm (2-in.) thick overlay was cast over an area of base concrete of $710 \times 1400 \mathrm{~mm}$ ( $28 \times 56 \mathrm{in.).} \mathrm{The} \mathrm{overlays} \mathrm{of} \mathrm{slab} \mathrm{Nos.}$ 2 and 3 were PCC and the overlay of Slab No. 1 was LMC. Prior to casting the overlay, the surface of the base concrete was sand blasted, and the surface of the base concrete was kept wet for a period of about 2 hours before placing the overlay. The overlay concrete materials were also cast in the $100 \mathrm{~mm}$ (4 in.) deep quarter sections $(710 \times 710 \mathrm{~mm}(28 \times 28 \mathrm{in.}))$ of the wood forms. A sketch of a typical slab showing areas where tensile tests were conducted for overlay over base concrete (O/B), overlay concrete only (O), and base concrete only (B) is given in Figure 1.

Concrete cylinders, 150 by $300 \mathrm{~mm}$ ( 6 by $12 \mathrm{in.),} \mathrm{were} \mathrm{cast,} \mathrm{stored,}$ and cured along with the concrete slabs at room temperature. The fresh concrete cylinders and slabs were moist cured for about seven days and air dried until tested.

The compressive cylinder strengths of the overlay concrete at the time of the tensile bond tests were 103, 86, and 81 percent of the compressive cylinder strengths of the base concrete in slabs No. 1, 2 , and 3, respectively. Table 2 gives the compressive cylinder strengths of concretes and their ages when tested. 
From 1 to 3 days prior to conducting the tensile tests, $57.2 \mathrm{~mm}$ ( 2.25 in.) diameter cores $64 \mathrm{~mm}$ ( $2.5 \mathrm{in.)}$ deep were drilled in the slabs using a nominal $64 \mathrm{~mm}$ ( $2.5 \mathrm{in.)}$ diameter core barrel. The centers of the cores were spaced $200 \mathrm{~mm}$ ( $8 \mathrm{in.}$ ) apart in both the length and width directions of the slabs. The cores were also located in the centers of the sections determined from the intersection of the reinforcing bars. Eighteen cores were drilled in the areas where overlay concrete was placed over base concrete, and nine cores were drilled in each of the overlay concrete only and base concrete only areas of the slabs (see Figure 1). After coring, ground concrete and sediment were washed out of the core holes with water using a hose.

\subsection{Test Apparatus and Procedures}

Tensile tests were performed on in situ cores drilled in the concrete slabs using pneumatic and hydraulic test methods. Alternate pneumatic and hydraulic test locations on the concrete slabs were adjacent to each other for purposes of comparing test results. The duration of each test was measured using a stopwatch to compute the rate of load application.

\subsubsection{Pneumatic Apparatus}

The pneumatic apparatus used in this study was a modification of an apparatus used to test the bond strength of coatings $[2,3]$. The major component of the pneumatic apparatus was a stainless steel piston with an air chamber. When the piston was pressurized, it provided a tensile force to the concrete core. A smaller diameter piston was used in previous studies for adhesion tests of coatings. The larger diameter piston used in this study was designed for the same maximum value of air pressure as in previous studies. In this study, the inside diameter of the piston was increased to $127 \mathrm{~mm}$ (5 in.) in order to provide a greater tensile force needed to test the concrete cores. A sketch of the pneumatic apparatus is shown in Figure 2. By controlling the air flow into the air chamber of the piston, the rate of applying the tensile force to the drilled core was controlled. The tensile force that could be applied was limited by the $0.690 \mathrm{MPa}$ (100 psi) air pressure in the piston air chamber, which corresponded to a maximum load of about $9800 \mathrm{~N}$ (2200 lbf). This value of maximum load was determined by calibration of the piston.

The following procedures were used for preparing the surface of the concrete core and for adhering a steel disk through which a tensile force was applied to the concrete core. The top surface of each core was cleaned with sand paper and then wiped with acetone and the surface was allowed to dry. Proper precautions were taken with the acetone, including care to prevent ignition of the acetone and proper handling procedures. Then a $12.7 \mathrm{~mm}(1 / 2 \mathrm{in.})$ thick by 
$50.8 \mathrm{~mm}$ (2 in.) diameter steel disk, containing a threaded steel stud, was adhered to the top surface of the core using a quicksetting, high-strength epoxy system ${ }^{1,2}$. The surface of the steel disk to be adhered was sandblasted to provide improved bond. Heaters with a blower and a capacity of 1500 watts were used to apply heat to the surface of the cores to assure that they were dry prior to applying epoxy. About 30 minutes of additional heating was applied to the epoxy system to accelerate the cure. A plastic enclosure was used to confine the heat to dry the tops of the concrete cores to enhance bonding and to further accelerate the cure of the epoxy. The steel disks were also heated prior to applying the epoxy.

The pneumatic test apparatus was assembled and attached to a core as shown in Figures 2 and 3. This apparatus included a brass bearing plate positioned over the steel disk, a rubber gasket moistened with water, and a piston screwed onto a threaded stud. As a safety precaution, a rubber sheet was secured over the assembled pneumatic apparatus to reduce the movement of the piston at failure (Figure $3 b$ ) and prevent damage to the piston. Introduction of air at the valve (Figure 2) resulted in (i) the silicone ${ }^{3}$ gasket being compressed and sealed on the rubber gasket, thus sealing the piston and (ii) the air chamber in the piston being pressurized, causing an upward tensile force on the threaded stud, the steel disk, and the core. After entering the intake channel, the air travelled over the compressed gasket to a diametrically opposite position from the air intake channel, where it entered the piston air chamber through another air channel (Figure 2). The chamber air pressure was increased at a uniform rate of $0.0076 \mathrm{MPa}(1.1 \mathrm{psi}) / \mathrm{sec}$, monitored with a pacing dial attached to a calibrated Heise air pressure gauge (Figure 4).

1 Certain manufacturers' names and names of commercial equipment, instruments, and materials are identified in this report to adequately describe the experimental procedure. Such an identification does not imply recommendation or endorsement by the National Institute of Standards and Technology, nor does it imply that the equipment, instruments, or materials identified are necessarily the best available for the purpose.

2 An epoxy-resin bonding system, Poly-Carb Mark-198, was used, and according to the manufacturer, it met the ASTM C 881 Specification for Type I, II, and III, Grade 3, Class A, B, or C type material and was a two-component $100 \%$ solids, moisture insensitive, epoxy-based system for use as a high-strength, nonshrink grouting material.

3 The silicone gasket was made from RTV11, a General Electric silicone rubber compound. 
Failure of the core occurred in the overlay, at the bond plane, or in the base concrete. The average load rate applied to the core itself was $5690 \mathrm{~N}$ (1280 lbf)/min. The load was applied until the core failed; the air pressure at failure was recorded.

The pneumatic apparatus was calibrated to obtain the relationship between air pressure in the piston and tensile force applied to the core. This relationship was used in determining the tensile core strengths. The setup for calibration is shown in Figure 5. During calibration, care was taken to assure that the threaded rod had ample clearance along its length.

\subsubsection{Hydraulic Apparatus}

The equipment described in ACI $503 \mathrm{R}$ [1] was modified from a mechanical to a hydraulic loading apparatus by the virginia Transportation Research Council (VTRC) and this modified apparatus was used in this study. The VTRC used the modified ACI 503R apparatus to test polymer concrete overlays which were 10 to $13 \mathrm{~mm}$ (0.4 to 0.5 in.) thick [4].

Similar procedures for surface preparation and adhesion of steel pipe caps for tensile load application were followed as described for the pneumatic device (Section 3.3.1). A steel pipe cap with a flat, $50.8 \mathrm{~mm}$ (2 in.) diameter, machined bottom surface (sandblasted to provide better bond), was adhered with epoxy to the top of the core.

The hydraulic apparatus was positioned as shown in Figure 6, with a template used to center the core with respect to the hydraulic apparatus. A plug with an attached hook was screwed into a pipe cap adhered to the top of a core. The hook was connected to a calibrated dynamometer and the dynamometer was connected to a hydraulic jack. The load was carefully applied manually using a lever attached to the hydraulic jack (Figure 6). However, due to limitations of the apparatus, the load rate varied somewhat, particularly at higher loads near failure. A stopwatch was used to control the rate of applied load at regular time and load intervals. The average load rate applied to the cores was 5340 $\mathrm{N} / \mathrm{min}$. (1200 lbf/min.). The load at failure was recorded from a load-tracking hand on the calibrated dynamometer, which had a 8896 N (2000 lbf) capacity.

\section{Test Results}

\subsection{Tensile Test Data}

Data are presented in Tables 3 to 5 for individual core specimens and the data are graphically shown in Figure 7. These tables include tensile core strengths for overlay over base concrete 
(O/B), overlay concrete only (O), and base concrete only (B). Table 6, which is a summary of tensile test data, includes the concrete compressive strength and test age of overlay and base concrete for each of the three slabs.

Failure locations in the concrete cores are included in Tables 3 to 5. Figures 8 to 10 are photographs of the failed cores. In general, there was little difference in the failed core lengths using the pneumatic compared with the hydraulic test method for comparable tests for each of the slabs. It is noted that cores designated with " $R$ " were retested and only the initial values were included in the data analysis, except for one case (Table 5). A retest was performed only for those cases where failure occurred in the initial test at the interface of the epoxy and the surface of the core. Since the surface of the core experienced little damage, the steel disk or pipe cap was adhered again using epoxy and the tensile test was repeated. The initial values had the highest failure load values and were considered to be the most representative of the core strength. Retesting confirmed that the initial values be selected for data analysis.

Failure information for $\mathrm{O} / \mathrm{B}$ tensile core bond tests for the three slabs is summarized as follows. In Slab No. 1 (LMC overlay), the location of the failure almost always occurred in the base concrete. In slabs Nos. 2 and 3 (PCC overlay), failure location generally occurred either in the overlay concrete or at the bond interface. When comparing the pneumatic and hydraulic test methods with regard to failure locations in the O/B concrete cores, there was little difference in the failure locations in each of the three slabs.

\subsection{Data Analysis and Discussion}

The average, standard deviation, and coefficient of variation values for each set of specimens corresponding to $0 / B, 0$, and $B$ concretes for each slab tested are given in Table 6 .

Because the failure location almost always occurred in the base concrete in slab No. 1, the average tensile core strengths represent minimum bond strengths. Although the data do not represent the maximum bond strengths, the data are applicable for comparing the two test methods.

For slab Nos. 2 and 3, the number of failures at the bond interface were about the same as the number of failures not at the bond interface for each test method of each slab. In the data analysis, the average tensile core strength and variability were based on failures at both locations. Thus, the average tensile core strengths for Slab Nos. 2 and 3 represent minimum bond strengths. As with slab No. 1, the data do not represent maximum bond strengths, but are applicable for comparing the two test methods. 
The relatively close agreement between average strengths for the pneumatic and hydraulic test results, for each of the nine sets of data, is shown in Figure 7. Although the differences in the average strengths between the two test methods were only statistically significant in one $e^{4}$ of the nine cases, the average tensile strengths from all nine cases using the pneumatic method were slightly greater than those of the hydraulic method. The ratio of the average pneumatic to hydraulic strengths for all nine sets of data (Table 6) ranged from 1.04 to 1.22 , with an average of 1.10. An explanation for the higher average pneumatic strengths is that the pneumatic method provided a more uniform and controlled rate of loading and possibly less eccentricity than the hydraulic method.

With regard to precision, the coefficient of variation values of tensile core strength, with one exception, were less than 20 percent for both test methods and, in most cases, were not substantially different when comparing the two test methods (Table 6). The overall range of coefficient of variation values for the pneumatic method (6.0-19.9) was about the same as for the hydraulic method $(6.1-22.7)$.

The laboratory study demonstrated that the pneumatic and hydraulic test methods are viable methods for measuring the bond strength between a relatively thick (about $50 \mathrm{~mm}$ ( 2 in.)) overlay and its base concrete. The results of the pneumatic test method were judged to be comparable to the hydraulic test method since for equivalent sets of data:

- the average tensile strengths were not judged to be substantially different from an engineering viewpoint (ratio of average tensile strengths of the pneumatic to hydraulic test methods ranged from 1.04 to 1.22 ),

o the differences in the average strengths between the two test methods, with one exception, were not statistically significant, and

o in most cases, the coefficient of variation values were not substantially different, and thus the precision (repeatability) of the two test methods was considered comparable.

\section{Summary and Conclusions}

A laboratory study was conducted to investigate the feasibility of two tensile test methods as in situ field tests to measure the bond

4 The O/B data from Slab No. 3. This case had the highest ratio of the average pneumatic to hydraulic strengths of 1.22 . 
between overlay concrete and base concrete. Tests were performed on slabs having overlay concrete cast over previously cast base concrete. The compressive strength of the overlay concrete was varied while the base concrete had about the same compressive strength. Uniaxial hydraulic and pneumatic tensile tests were conducted using in situ cores drilled in the slabs to measure the tensile bond strength between the overlay concrete and base concrete, and to measure the tensile strength of the overlay and base concretes.

The conclusions from this laboratory study to investigate the feasibility of using hydraulic and pneumatic uniaxial tensile test methods as in situ field test methods are as follows:

1. A pneumatic apparatus, originally developed for measuring the adhesion of protective coatings, was modified successfully to measure the tensile bond strength of $57.2 \mathrm{~mm}$ (2.25 in.) diameter concrete cores.

2. The pneumatic and hydraulic test methods are feasible methods for use in the field for measuring the tensile bond strength between a relatively thick (about $50 \mathrm{~mm}$ ( 2 in.)) overlay and its base concrete. Although the test methods are feasible for field use, their applicability under varying field conditions needs to be demonstrated.

3. The results of the pneumatic test method were judged to be comparable to the hydraulic test method since for equivalent data sets:

- the average tensile strengths were not judged to be substantially different from an engineering viewpoint (ratio of average tensile strengths of the pneumatic to hydraulic test methods ranged from 1.04 to 1.22 ),

o the differences in the average strengths between the two test methods, with one exception, were not statistically significant, and

o with one exception, the coefficient of variation values were less than 20 percent for both test methods and, in most cases, were not substantially different.

4. Advantages of the pneumatic test method compared with the hydraulic test method are:

o the rate of load application was better controlled for the pneumatic test method, and

o the pneumatic test method has the potential to be used on horizontal, vertical or overhead surfaces. Hydraulic test methods [14-16] other than the one investigated and 
mechanical test methods [17-19] have potential for use on vertical and overhead surfaces.

5. Both test methods investigated were judged to be applicable for overlay materials other than those included in this study, provided adequate bonding can be developed between the steel disk or pipe cap and the top of the overlay. Factors affecting the bond of the steel disk or pipe cap to the overlay need to be considered, including the effects of the water used for coring and the application of heat (if used) to cure the epoxy.

\section{Recommendations}

1. The feasibility of using the pneumatic and hydraulic test methods to measure in situ the tensile bond strength of overlays to base concrete in the field should be evaluated, particularly in adverse environmental conditions (e.g., wet surfaces, or cool or cold temperatures). It is noted that preliminary field data have been obtained by NIST to evaluate the feasibility of both test methods to measure the tensile bond strength of portland cement concrete and latex modified concrete bridge deck overlays but the data are as yet unpublished.

2. Use of the test methods to measure the tensile bond strength of overlay thicknesses in excess of about $50 \mathrm{~mm}$ ( $2 \mathrm{in.}$ ) needs to be investigated, since other factors, such as eccentricity, may affect the magnitude or precision or both. For example, methods or apparatus should be developed for reducing the eccentricity.

3. In situ, uniaxial test methods to evaluate the tensile bond strength of repair materials on surfaces other than horizontal should be evaluated.

\section{Acknowledgments}

This investigation was conducted under the Tri-service Building Materials Investigational Program and was jointly sponsored by the Headquarters, U.S. Army Corps of Engineers; U.S. Navy, Naval Facilities Engineering Command; and Headquarters, U.S. Air Force, Engineering and Services.

The authors gratefully acknowledge the assistance of Frankie Davis, Nathaniel E. Waters, Edgardo Colon, and Curtis spring for casting and preparing slabs and performing tests. Special thanks are expressed to Frankie Davis and James seiler who provided ideas and suggestions for improving the test procedures. The authors also thank their NIST colleagues, James clifton, Geoffrey Frohnsdorff, James Pielert, and Nicholas Carino, who gave important review comments. The statistical consultation provided by James $J$. Filliben of NIST is also acknowledged. Finally, the authors 
appreciate the support of Denise Herbert for typing the tables.

\section{References}

1. "Use of Epoxy Compounds with Concrete," Appendix A, ACI 503R-89, 1990 ACI Manual of Concrete Practice - Part 5, American Concrete Institute, Detroit, Michigan, 1990.

2. Seiler, J. F., McKnight, M. E. and Masters, L. W. "Development of a Test Apparatus and Method for Measuring Adhesion of Protective Coatings," NBSIR 82-2535, National Bureau of Standards, July 1982.

3. U. S. Patents: No. 4,393, 699 Pneumatic Adhesion Tester, July 19, 1983; No. 4,491,014 Bond Testing Apparatus, Jan. 1, 1985; No. 4,494,563 Fluid Safety Valve, Jan. 22, 1985 .

4. Sprinkel, M. M., "Evaluation of the Construction and Performance of Multiple Layer Polymer Concrete Overlays, Interim Report No. 2, Condition of the Overlays after Five Years in Service," Virginia Transportation Research Council, Report VTRC 87-R28, May, 1987.

5. Hutchinson, R. L., "Resurfacing with Portland Cement Concrete," NCHRP Synthesis of Highway Practice 99, Transportation Research Board, Dec., 1982 .

6. Knab, L. I., Sprinkel, M. M., and Lane, O. J., "Preliminary Performance Criteria for the Bond of Portland-Cement and LatexModified Concrete Overlays," NISTIR 89-4156, National Institute of Standards and Technology, Nov., 1989.

7. Rizzo, E. M. and Sobelman, M. B., "Selection Criteria for Concrete Repair Materials," ACI Concrete International, Sept., 1989 .

8. Wall, J.S. and Shrive, N. G., "Factors Affecting Bond Between New and Old Concrete," ACI Materials Journal, March-April, 1988, pp. $117-125$.

9. Collins, F. G. and Roper, H., "Evaluation of Concrete Spall Repairs by Pullout Test," RILEM, Materials and structures,22, 1989 ,pp. 280-286.

10. Knab, I. I. and Spring, C. B., "Evaluation of Test Methods for Measuring the Bond Strength of Portland Cement Based Repair Materials to Concrete," Cement, Concrete, and Aggregates, summer 1989, ASTM, Phil. PA. pp.3-14.

11. Knab, L. I., "Factors Related to the Performance of Concrete Repair Materials," Repair, Evaluation, Maintenance, and Rehabilitation Research Program, Technical Report REMR-CS-12, U. S. Army Corps of Engineers, Wash DC, 20314-1000, March, 1988. 
12. AASHTO, Standard Method for Testing Epoxy Resin Adhesive, AASHTO T 237-73 (1982), AASHTO, Wash. D.C.

13. "Method of Test for Determining the Shearing Strength of Bonded Concrete," Test Method No. Iowa 406-B, September 1984, Iowa Department of Transportation, Highway Division (2 pages).

14. Causey, F. E., "Preliminary Evaluation of a Tension Test for Concrete Repairs," Report No. GR-83-14, Bureau of Reclamation, Denver CO., Dec. 1984 .

15. Hindo, K. R., "In-Place Bond Testing and Surface Preparation of Concrete," ACI, Concrete International, Apr.1990, pp. 46-48.

16. Peterson, C. G.,"New Bond Testing Method Developed," Concrete Repair Bulletin, International Association of concrete Repair Specialists, Sept. 1990.

17. Murray A. MCC. and Long, A. E., A Study of the In-Situ Variability of Concrete Using the Pull-off Method," Proc. Instn. Civ. Engrs., Part 2, 83, Dec. 1987, pp. 731-745.

18. Long, A. E. and Murray, A. MCC., "The 'Pull-off'Partially Destructive Test for Concrete," ACI SP-82, American Concrete Institute, Detroit Michigan, 1984, pp. 327-350.

19. Schulz, R.-R., "Repair Work - Criteria for Planning and Tendering," Betonwerk und Fertigteil-Technik, Vol. 53, No.8, 1987, pp. 574-582.

20. Davey, R. A. and Boserio, I. M., "Expansion Admixture for Masonry Wall Grouts," Ministry of Works and Development, Report No. 4-78/1, Central Laboratories, New Zealand, August 1978. 
Table 2. Compressive Cylinder Strength and Age of Base and Overlay Concrete

$$
\text { Base concrete Overlay concrete }
$$

\begin{tabular}{ccccccc} 
Slab No. & Type & $\begin{array}{c}\text { Age } \\
\text { (days) }\end{array}$ & $\begin{array}{c}\text { Strength } \\
\text { MPa }\end{array}$ & Type & $\begin{array}{c}\text { Compressive } \\
\text { Strength } \\
\text { (psi) }\end{array}$ \\
\hline 1 & PCC & 76 & $31.8(4610)$ & LMC $^{\text {M }}$ & 14 & $32.9(4770)$ \\
2 & PCC & 69 & $31.8(4620)$ & PCC & 28 & $27.4(3980)$ \\
3 & PCC & 48 & $30.3(4390)$ & PCC & $7-8$ & $24.4(3540)$
\end{tabular}

\begin{abstract}
aPCC denotes portland cement concrete.
bIMC denotes latex modified concrete.
\end{abstract}


Table 3. Tensile Test Data for Slab Number 1

\begin{tabular}{|c|c|c|c|}
\hline $\begin{array}{l}\text { Core }^{a} \\
\text { Number }\end{array}$ & Concrete ${ }^{b}$ & $\begin{array}{l}\text { Pneu } \\
\mathrm{MPa}\end{array}$ & $\begin{array}{l}\text { atic } \\
\text { (psi) }\end{array}$ \\
\hline 1 & $O / B$ & 2.39 & $(346)$ \\
\hline 3 & $0 / B$ & 2.83 & (411) \\
\hline 10 & $0 / B$ & 1.88 & (272) \\
\hline 12 & $0 / B$ & 2.17 & (315) \\
\hline 5 & $O / B$ & 2.11 & $(306)$ \\
\hline
\end{tabular}

$$
\begin{array}{ll}
1.73 & (251) \\
2.36 & (342) \\
2.12 & (307) \\
1.97 & (286) \\
2.43 & (352) \\
2.46 & (357) \\
1.59 & (231)
\end{array}
$$

27

$\begin{array}{ll}22 & 0 \\ 26 & 0 \\ 24 & 0 \\ 20 & 0\end{array}$

34

28

30

32

36

$\begin{array}{ll}31 & B \\ 31 R^{d} & B \\ 33 & B \\ 29 & B \\ 35 & B\end{array}$

$\begin{array}{lll}0 & 3.05 & (442) \\ 0 & 3.57 & (518) \\ 0 & 3.05 & (442) \\ 0 & 3.52 & (511) \\ 0 & 2.93 & (425)\end{array}$

$3.39(492)$

$2.98(432)$

$2.94(427)$

$2.84(412)$

$\begin{array}{ll}2.17 & (315) \\ 2.30 & (334) \\ 1.79 & (259) \\ 1.49 & (216) \\ 2.28 & (330)\end{array}$

$2.17(315)$

B $\quad 2.30(334)$

B $1.79(259)$

B $1.49(216)$

B $2.28(330)$

$$
\begin{array}{ll}
1.72 & (249) \\
1.59 & (231) \\
1.70 & (246) \\
1.80 & (261) \\
1.94 & (281)
\end{array}
$$

Failure Location

base concrete $80 \%$ base concrete ${ }^{c}$ 95\% base concrete ${ }^{c}$ base concrete base concrete base concrete

base concrete base concrete base concrete base concrete 95\% overlay concrete ${ }^{c}$ base concrete base concrete

overlay concrete overlay concrete overlay concrete overlay concrete overlay concrete

overlay concrete overlay concrete overlay concrete overlay concrete

base concrete base concrete base concrete base concrete base concrete

top of concrete base concrete base concrete base concrete base concrete

a Failed cores shown in Figure 8 .

${ }^{b}$ Compressive strengths of IMC overlay and PCC base were 32.9 and $31.8 \mathrm{MPa}$ ( 4770 and $4610 \mathrm{psi}$ ), respectively. Ages when tested of overlay and base were 14 and 76 days, respectively. O/B represents tensile bond tests of overlay on base concrete; O represents tensile tests of overlay concrete only; B represents tensile tests of base concrete only.

${ }^{c}$ Remainder failed at bond/interface.

$\mathrm{d}_{31 \mathrm{R}}$ was a retest of 31 ; since the strength of 31 was higher than $31 \mathrm{R}$, the strength of 31 was included in the data analysis and $31 \mathrm{R}$ was omitted. 
Table 4. Tensile Test Data for Slab Number 2

Core ${ }^{a}$

Tensile strength

Number

Pneumatic Hydraulic

$\mathrm{MPa}$ (psi) $\mathrm{MPa}$ (psi)

Failure Location

$\begin{array}{rrrr}5 & \text { O/B } & 1.95 & (283) \\ 17 & \text { O/B } & 2.63 & (381) \\ 10 & \text { O/B } & 2.17 & (315) \\ 3 & \text { O/B } & 1.66 & (241) \\ 15 & \text { O/B } & 1.71 & (248) \\ 1 & \text { O/B } & 2.14 & (311) \\ 8 & \text { O/B } & 1.79 & (260)\end{array}$

$\begin{array}{cccc}18 & \text { O/B } & & \\ 18 \mathrm{R}^{\mathrm{d}} & \text { O/B } & & \\ 6 & \text { O/B } & & \\ 11 & \text { O/B } & & \\ 4 & \text { O/B } & & \\ 16 & \text { O/B } & & \\ 9 & \text { O/B } & & \\ 2 & \text { O/B } & & \\ 7 & \text { O/B } & & \\ 14 & \text { O/B } & & \\ & & & \\ 36 & \text { O } & 1.67 & (242) \\ 32 & \text { O } & 1.43 & (207) \\ 34 & \text { O } & 2.27 & (329) \\ 28 & 0 & 1.75 & (254)\end{array}$

$2.36(342)$

1.80 (261)

1.18 (171)

$1.79(260)$

$1.70(246)$

$2.15(312)$

$2.32(337)$

1.87 (271)

$1.83(266)$

1.28 (185)

1.67 (242)

1.43 (207)

$1.75(254)$

33

35

31

29

21

19

23

25

24

26

22
0
0
0
0

B
B
B
B

$1.82(264)$

$1.53(222)$

$1.75(254)$

1.64 (238)

${ }^{a}$ Failed cores shown in Figure 9.

${ }^{b}$ Compressive strengths of PCC overlay and PCC base were 27.4 and $31.8 \mathrm{MPa}$ ( 3980 and 4620 psi), respectively. Ages when tested of overlay and base were 28 and 69 days, respectively. O/B represents tensile bond tests of overlay on base concrete; 0 represents tensile tests of overlay concrete only; $B$ represents tensile tests of base concrete only.

${ }^{c}$ For core number 17, failure occurred at two locations in overlay concrete; for core number 15, combination bond/interface and base concrete failure. $\mathrm{d}_{18 \mathrm{R}}$ was a retest of 18 ; since the strength of 18 was higher than $18 \mathrm{R}$, the strength of 18 was included in the data analysis and 18R was omitted. 
Table 5. Tensile Test Data for Slab Number 3

\begin{tabular}{|c|c|c|c|}
\hline Core $^{a}$ & & Pne & $\begin{array}{l}\text { Tensi } \\
\text { latic }\end{array}$ \\
\hline Number & Concrete ${ }^{b}$ & $\mathrm{MPa}$ & (psi) \\
\hline 5 & $0 / B$ & 2.45 & $(355)$ \\
\hline 17 & $0 / B$ & 1.98 & (287 \\
\hline 8 & $O / B$ & 1.90 & $(275)$ \\
\hline 13 & $0 / \mathrm{B}$ & 1.63 & $(236)$ \\
\hline 15 & $0 / B$ & 1.84 & $(267)$ \\
\hline 10 & $O / B$ & 2.08 & $(301)$ \\
\hline 12 & $O / B$ & 1.61 & $(234)$ \\
\hline 3 & $0 / B$ & 2.07 & $(300)$ \\
\hline 1 & $O / B$ & 1.75 & $(25$ \\
\hline
\end{tabular}

$\begin{array}{rrrr}4 & \text { O/B } & 1.70 & (246) \\ 18 & \text { O/B } & 1.59 & (231) \\ 2 & \text { O/B } & 1.63 & (236) \\ 9 & \text { O/B } & 1.42 & (206) \\ 7 & \text { O/B } & 1.66 & (241) \\ 6 & \text { O/B } & 1.70 & (246) \\ 11 & \text { O/B } & 1.42 & (206) \\ 16 & \text { O/B } & 1.11 & (161) \\ 14 & \text { O/B } & 1.90 & (276)\end{array}$

$1.82(264)$

$2.07(300)$

$2.00(290)$

$2.08(302)$

$\begin{array}{ll}1.87 & (271) \\ 1.90 & (276) \\ 2.08 & (302) \\ 1.66 & (241)\end{array}$

$2.09(303)$

d

$2.58 \quad(374)$

$2.36(343)$

$2.04 \quad(296)$

1.79 (259)

2.27 (329)
Hydraulic

$\mathrm{MPa}$ (psi)

Failure Location

bond/interface overlay concrete bond/interface overlay concrete overlay concrete overlay concrete bond/interface bond/interface $c$

bond/interface bond/interface base concrete overlay concrete overlay concrete bond/interface overlay concrete bond/interface bond/interface

overlay concrete overlay concrete overlay concrete overlay concrete

overlay concrete overlay concrete overlay concrete overlay concrete

base concrete d

epoxy/concrete base concrete base concrete base concrete epoxy/concrete

$\begin{array}{ll}1.80 & (261) \\ 2.19 & (317) \\ 2.01 & (291) \\ 2.12 & (307) \\ 1.45 & (211)\end{array}$

base concrete epoxy/concrete base concrete base concrete base concrete

${ }^{a}$ Failed cores shown in Figure 10.

${ }^{b}$ Compressive strengths of PCC overlay and PCC base were 24.4 and $30.3 \mathrm{MPa}$ ( 3540 and $4390 \mathrm{psi}$ ), respectively. Ages when tested of overlay and base were $7-8$ and 48 days, respectively. O/B represents tensile bond tests of overlay on base concrete; O represents tensile tests of overlay concrete only: B represents tensile tests of base concrete only.

combination bond/interface and base concrete.

do data.

$e_{34 R}$ was a retest of $34 ; 34 R R$ was a retest of $34 R$. Since the strength of $34 R$ was higher than $34 R R$ and data were not obtained for $34,34 R$ was included in the data analysis and the other two omitted.

$f_{31 R}$ was a retest of 31 ; since the strength of 31 was higher than that of $31 R$, the strength of 31 was included in the data analysis and $31 R$ was omitted. 


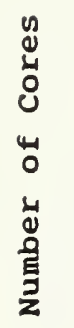

究 $+\infty$

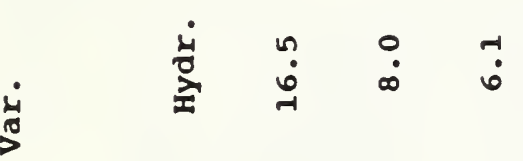

$\stackrel{\dot{\sim}}{\stackrel{\sim}{\sim}} \stackrel{\dot{\sim}}{ }$

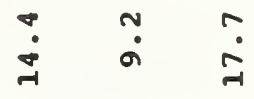

过

$\stackrel{\infty}{\dot{\sigma}} \quad \stackrel{a}{n} \quad \stackrel{n}{n}$

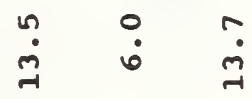

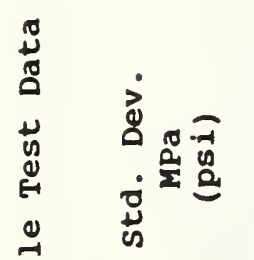

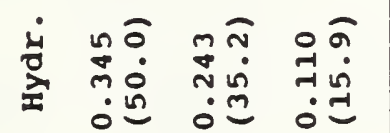

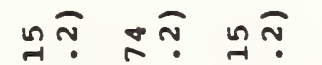

กิก

:응

jँ

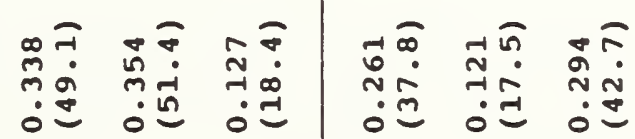

$\stackrel{0}{\mathrm{E}}$

要

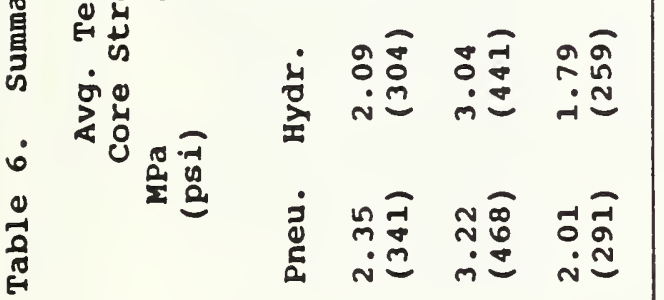

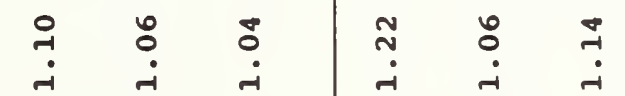

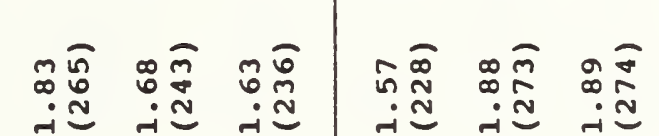

ํํำ

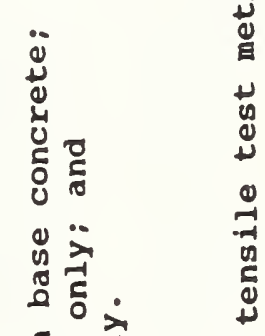

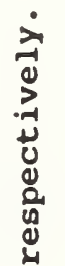

赵营

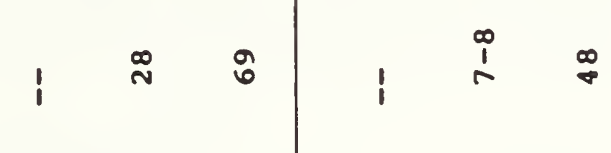

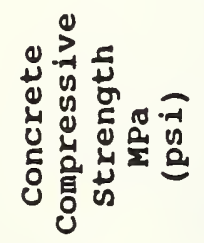

ㄱำ

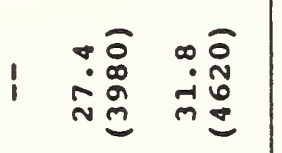

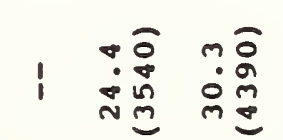

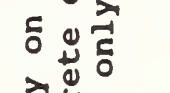

至岀苟

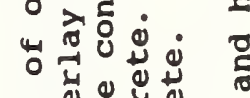



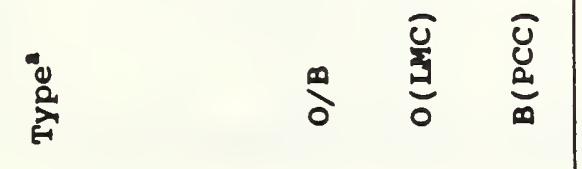

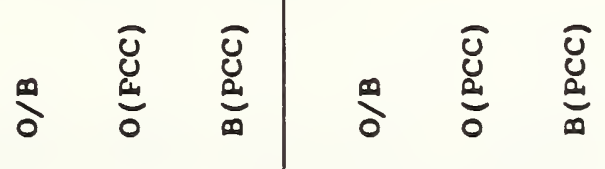

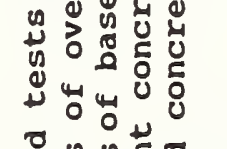

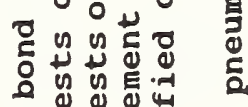

(4) ه

न

苋

ฮู้อ

计

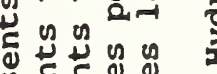

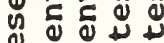

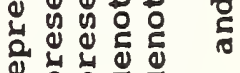

䟢运

$N$

운

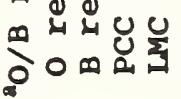

कृ 


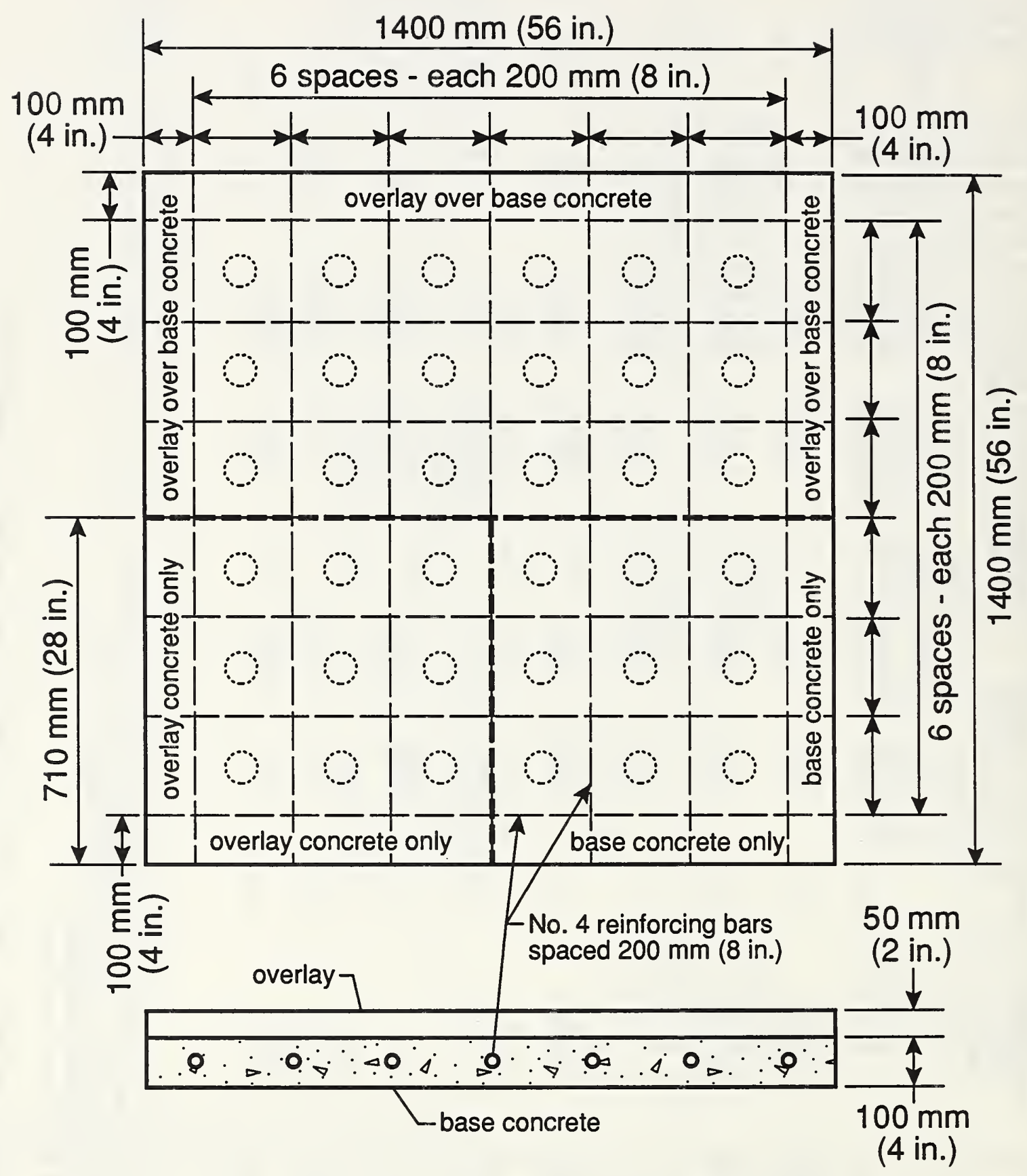

Figure 1. Typical Concrete Slab Used for the Tensile Tests of Drilled Cores. 


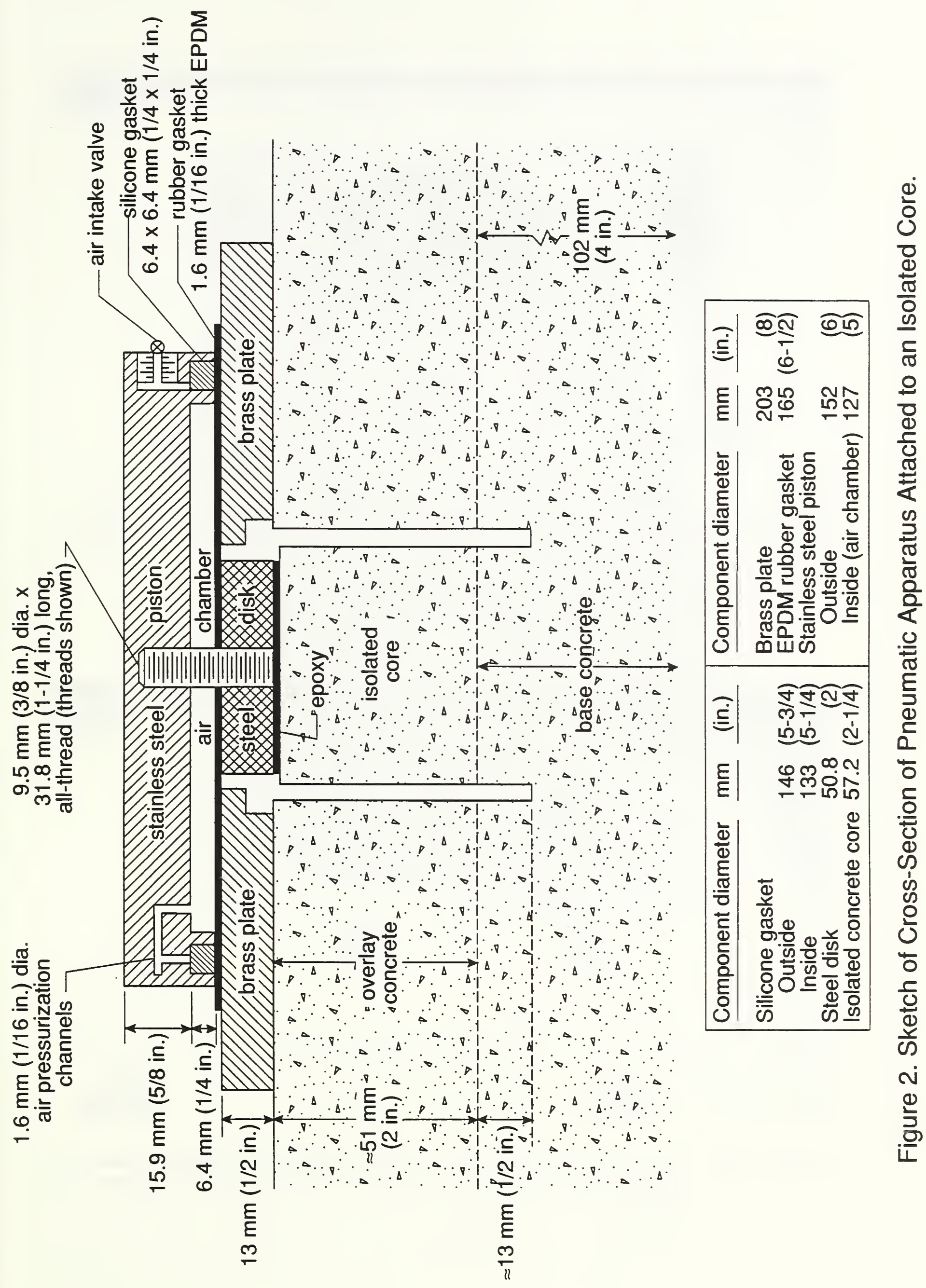



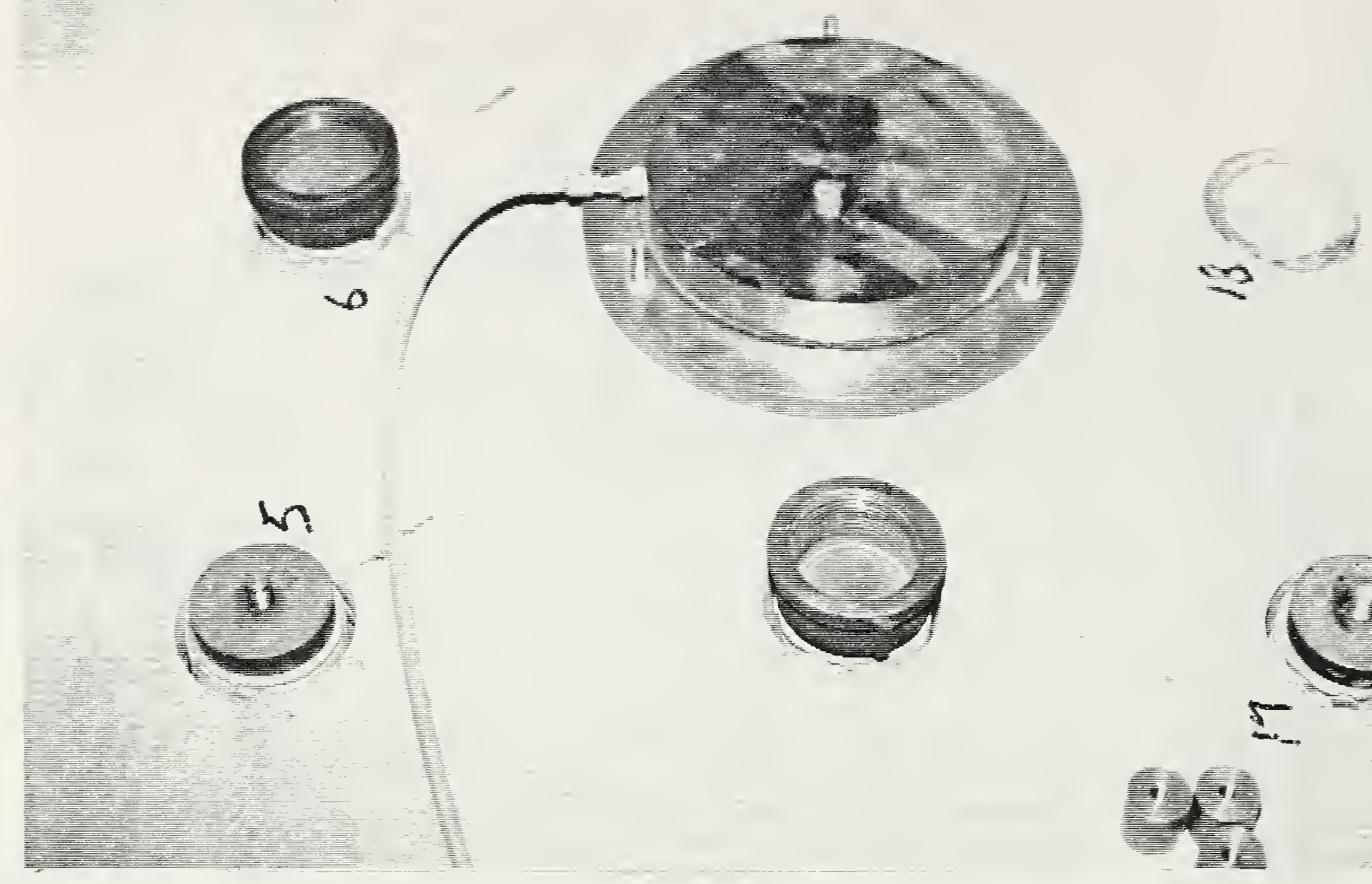

Figure 3a. Pneumatic Apparatus Positioned for Testing.

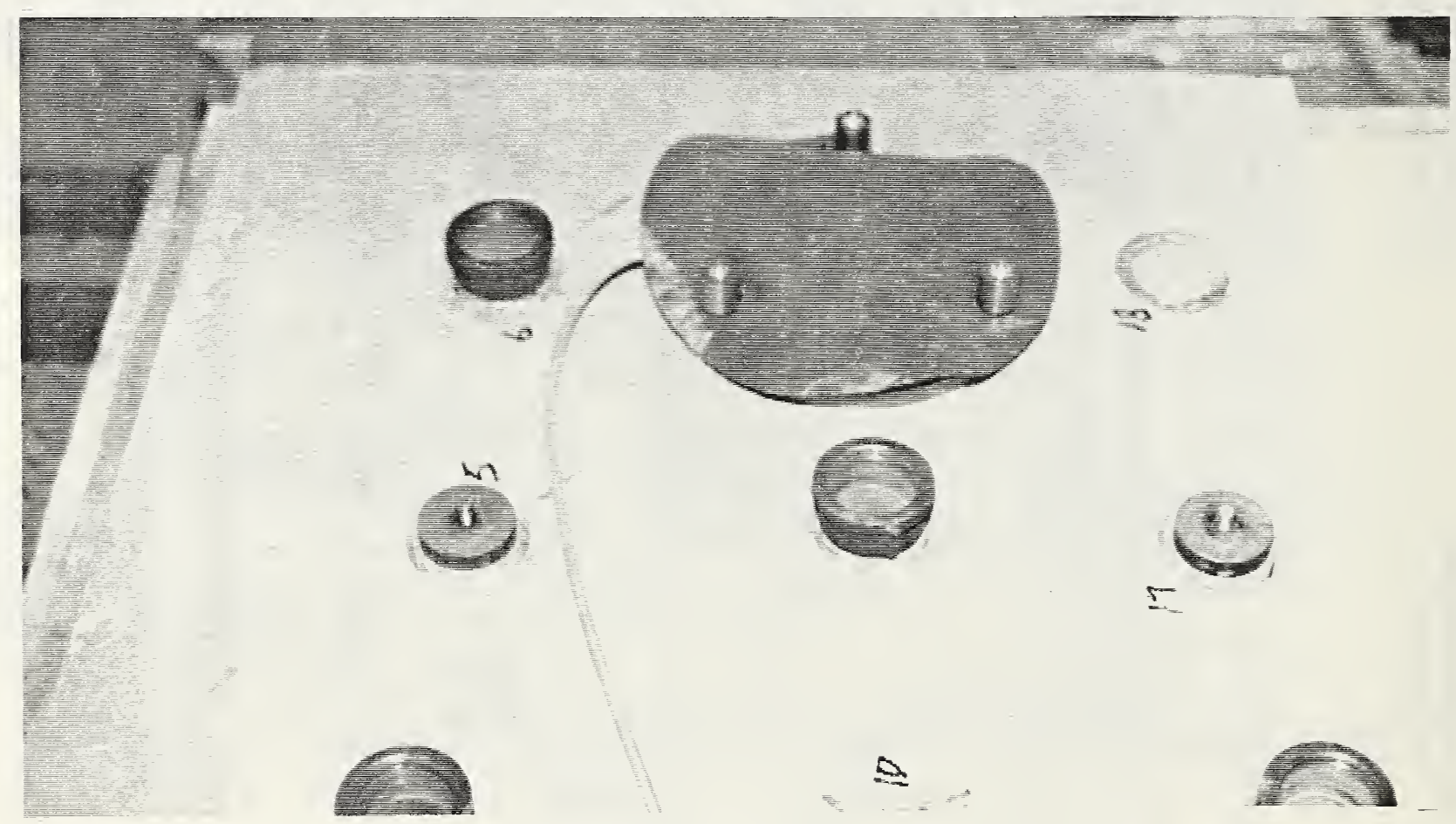

Figure 3b. Pneumatic Apparatus with Attached Rubber sheet to Reduce Movement at Failure and Prevent Damage to Piston. 


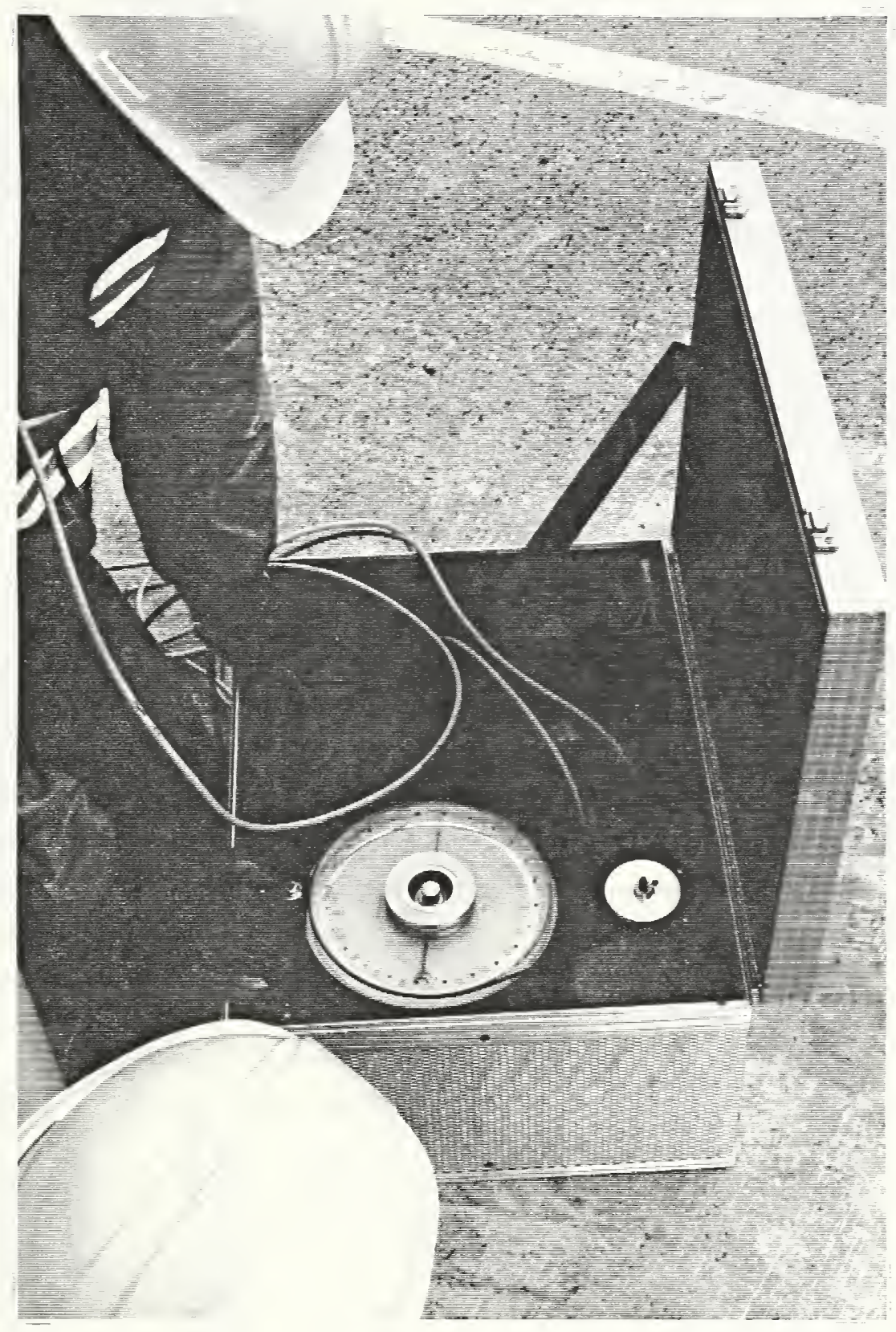

Figure 4. Heise Air Pressure Gauge with Pacing Dial used to Pressurize Piston Air Chamber at a Uniform Rate. 


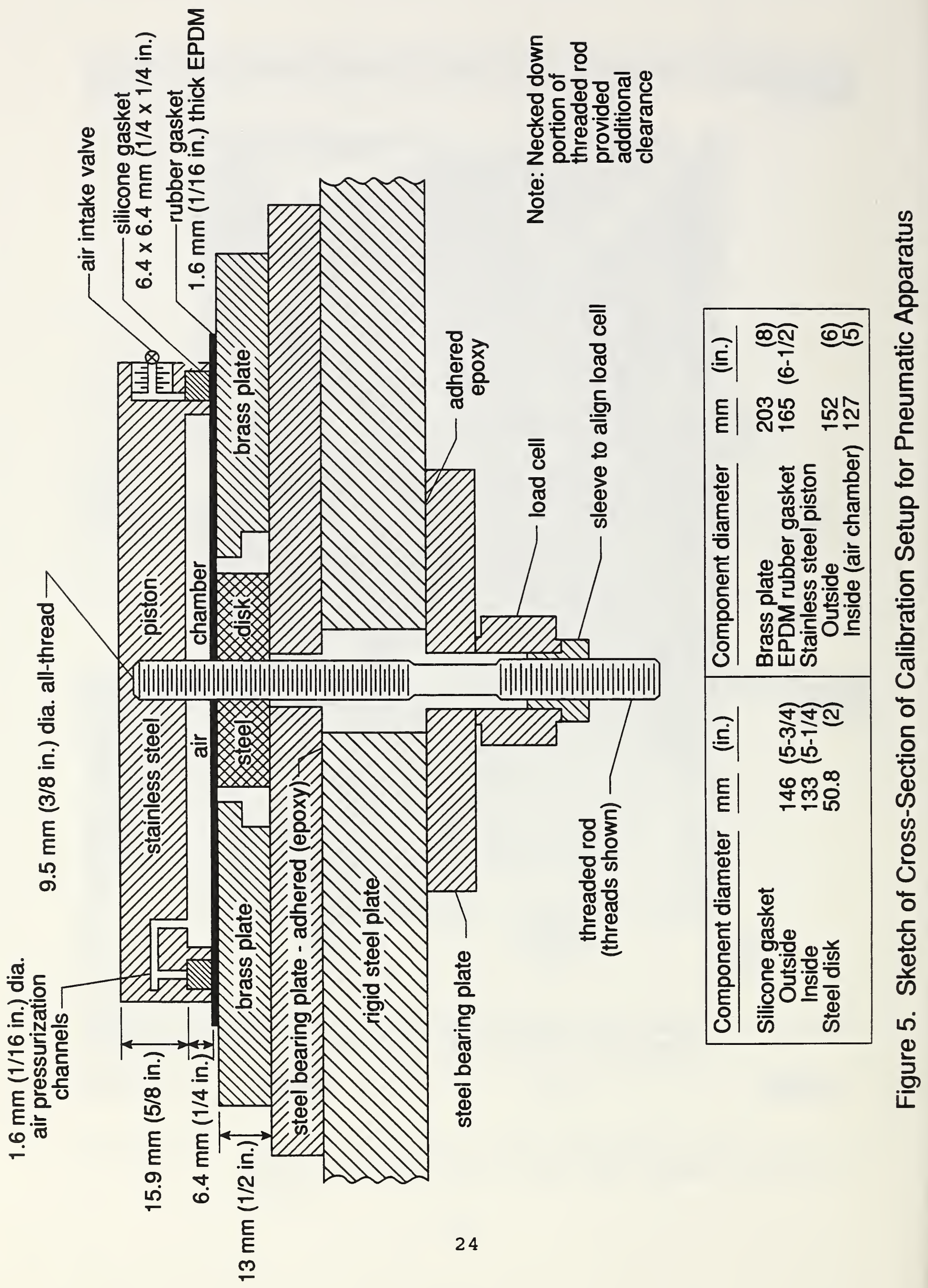




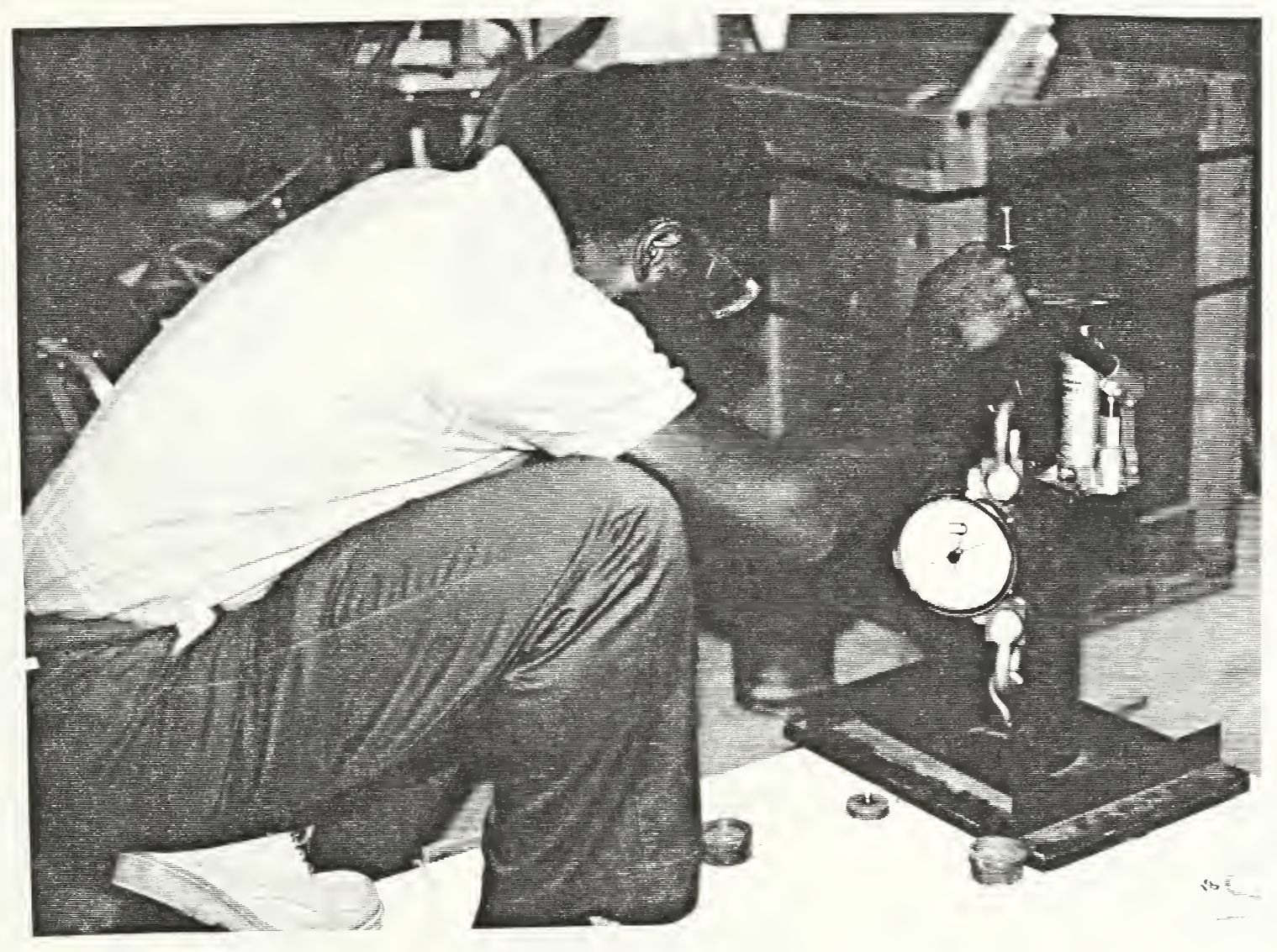

Figure 6. Hydraulic Apparatus Positioned for Testing. 


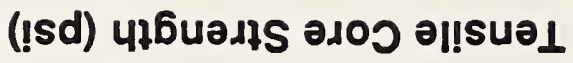

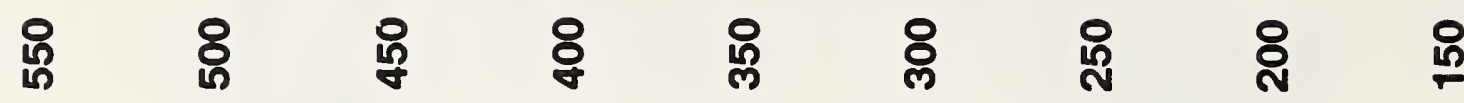

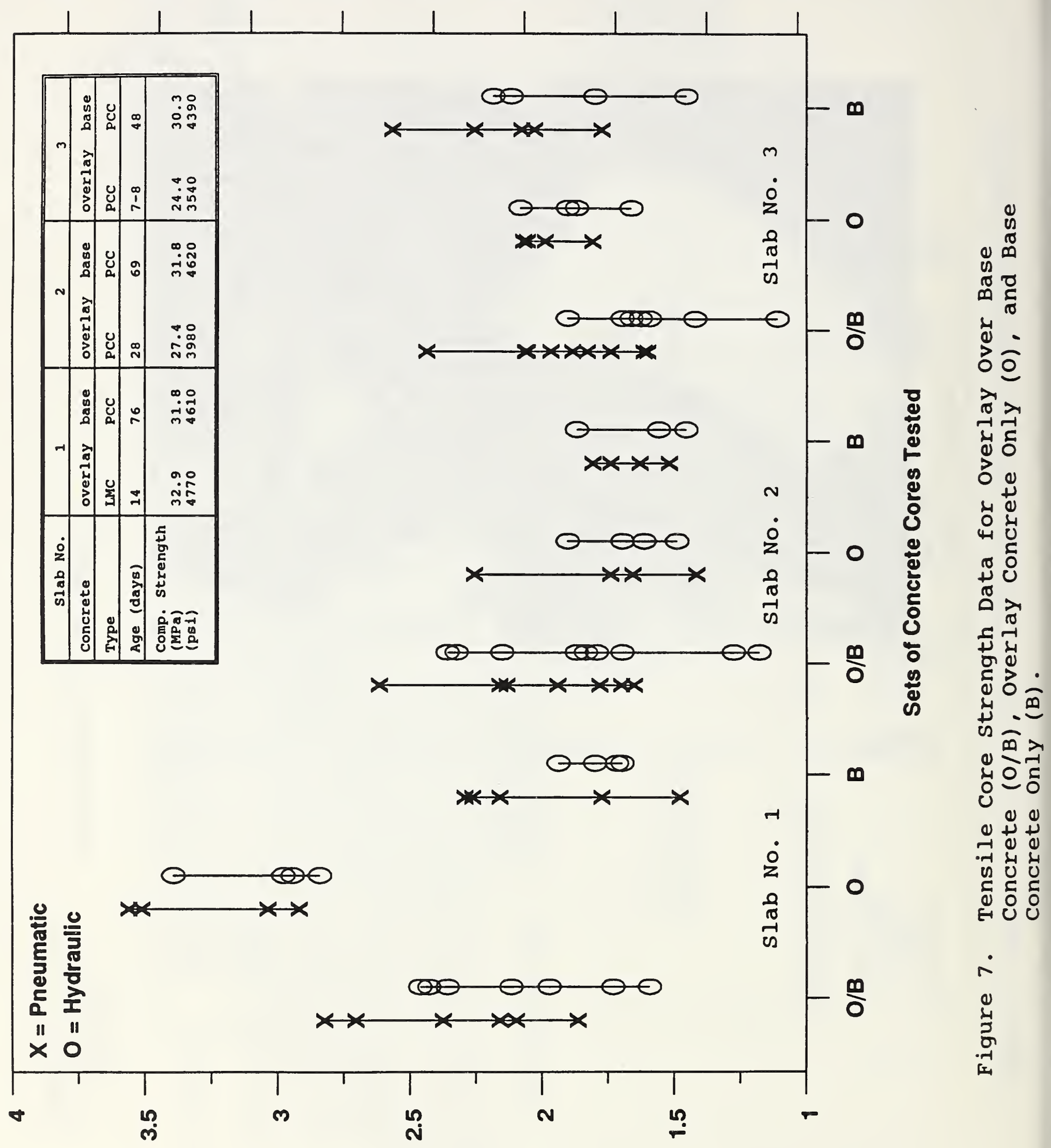

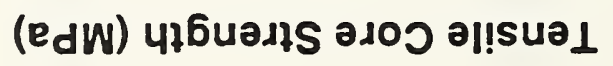



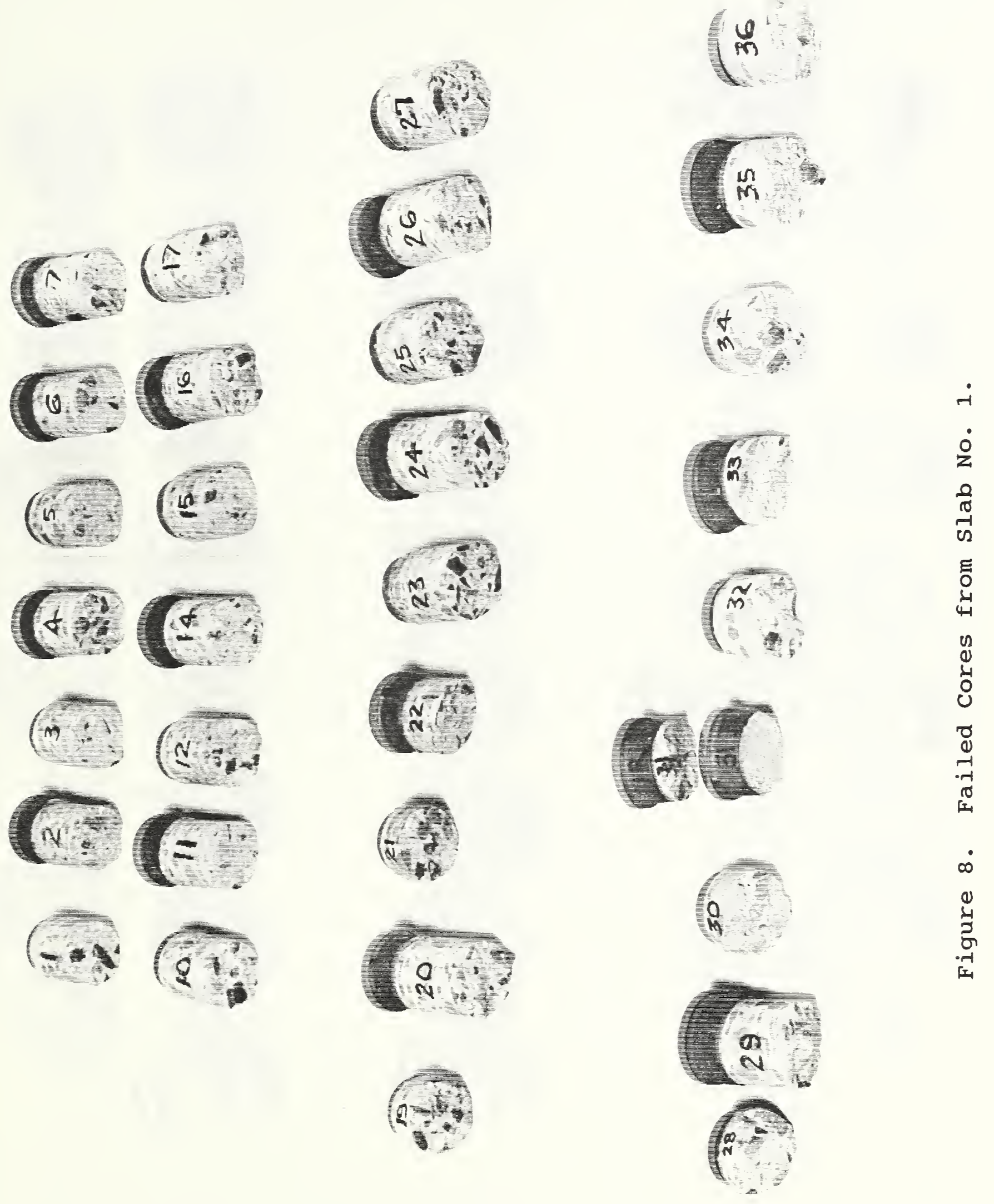

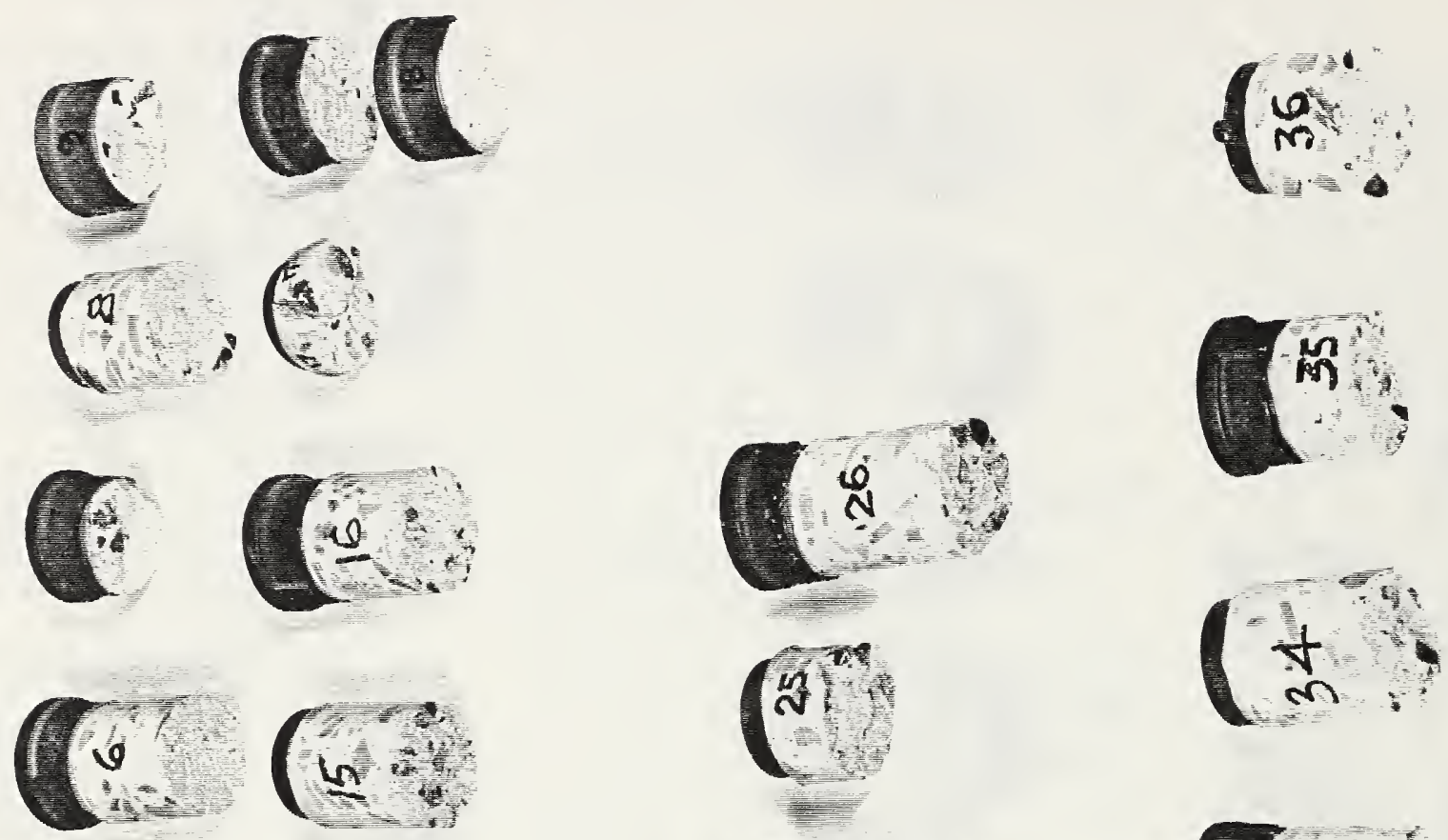

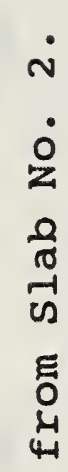
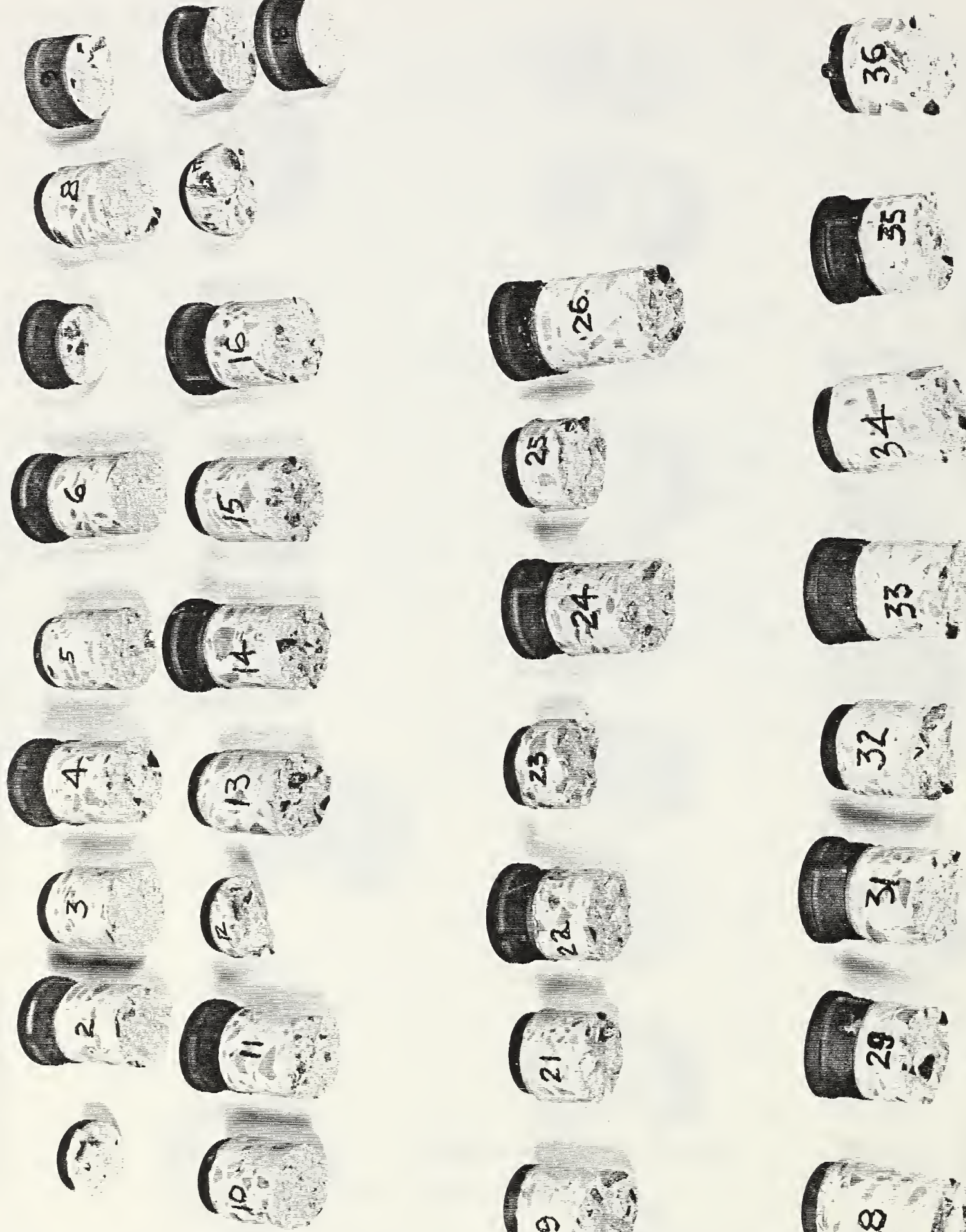

0
0
0
0
0

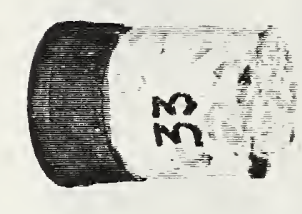

$\underset{-1}{-1}$

ले

के

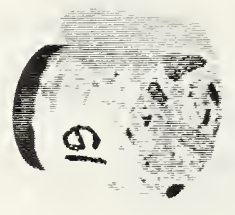

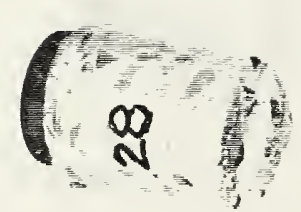



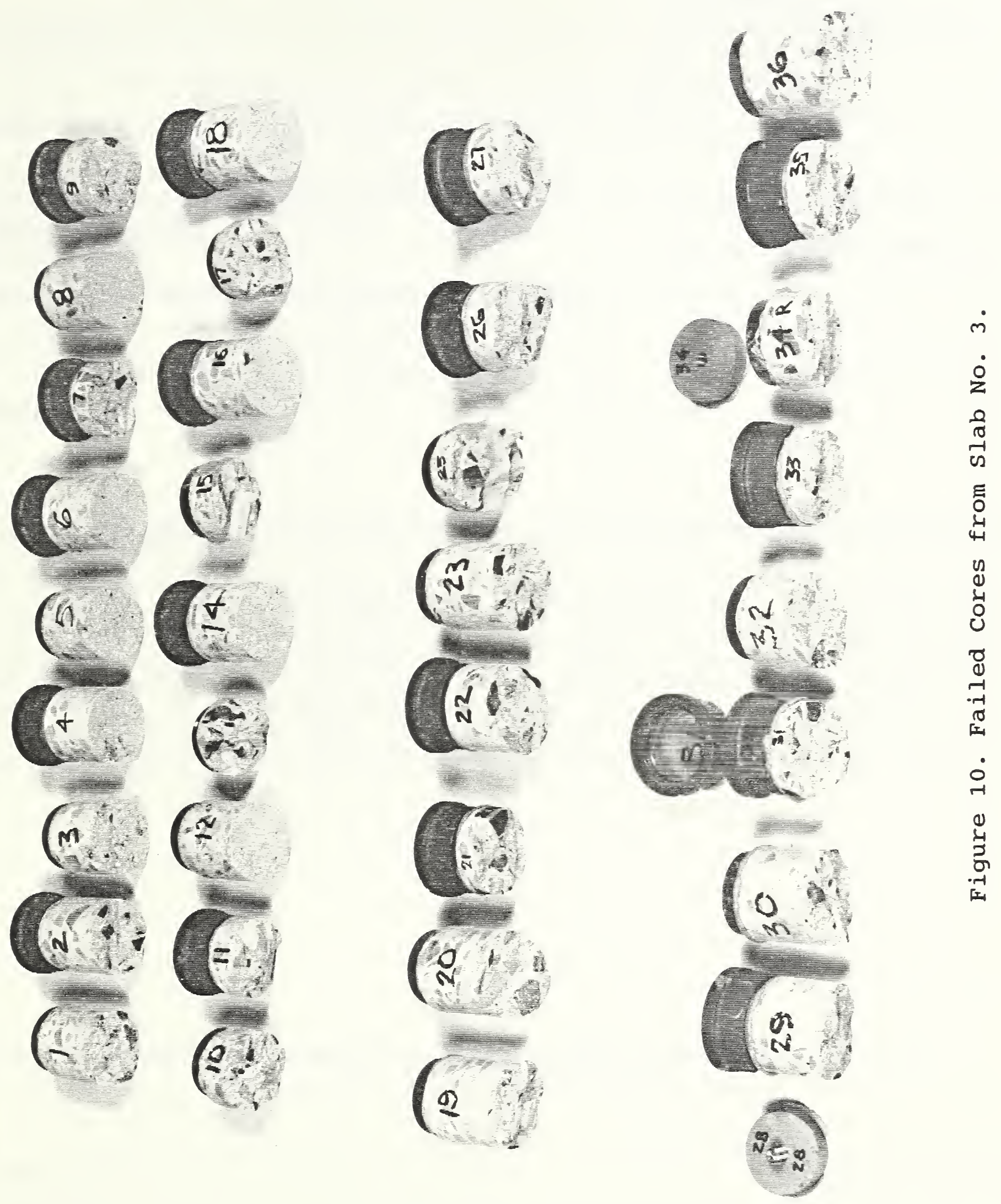


